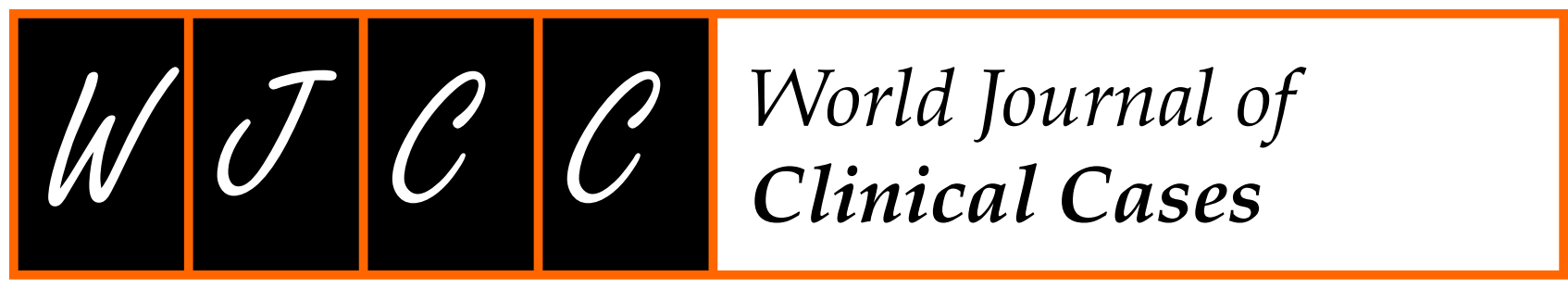

Submit a Manuscript: https:/ / www.f6publishing.com

World J Clin Cases 2021 September 16; 9(26): 7762-7771

Randomized Controlled Trial

\title{
Impact of intravenous dexmedetomidine on postoperative bowel movement recovery after laparoscopic nephrectomy: A consort- prospective, randomized, controlled trial
}

Shan-Shan Huang, Fu-Xi Song, Shao-Zhong Yang, Shuai Hu, Lian-Ying Zhao, Shu-Qin Wang, Qi Wu, Xin Liu, Feng Qi

ORCID number: Shan-Shan Huang 0000-0001-5587-9989; Fu-Xi Song 0000-0002-2835-6047; Shao-Zhong Yang 0000-0003-4958-1232; Shuai Hu 0000-0002-6059-7625; Lian-Ying Zhao 0000-0002-6733-7092; Shu-Qin Wang 0000-0001-8079-045X; Qi Wu 0000-0001-8406-0526; Xin Liu 00000002-1025-5846; Feng Qi 0000-00020272-493X.

Author contributions: Qi F, Huang SS, Yang SZ, and Hu S performed the research; Zhao LY helped to analyze the data; Song FX and Wang SQ helped to collect the data; Huang SS provided imaging data; Huang SS, Wu Q, and Liu X analyzed the data and wrote the manuscript; all the authors proofread the manuscript.

Supported by the National Natural Science Foundation of China, No. 81672250; and the Fundamental Research Funds of Shandong University.

\section{Institutional review board} statement: The trial was authorized by the Institutional Medical Ethics Committee of Qilu Hospital of Shandong University.

Clinical trial registration statement: This study was registered at
Shan-Shan Huang, Shao-Zhong Yang, Lian-Ying Zhao, Shu-Qin Wang, Qi Wu, Xin Liu, Feng Qi, Department of Anesthesiology, Qilu Hospital, Cheeloo College of Medicine, Shandong University, Jinan 250012, Shandong Province, China

Fu-Xi Song, Shuai Hu, Department of Anesthesiology, The Second Hospital, Cheeloo College of Medicine, Shandong University, Jinan 250033, Shandong Province, China

Corresponding author: Feng Qi, MD, Chief Physician, Department of Anesthesiology, Qilu Hospital, Cheeloo College of Medicine, Shandong University, No. 107 Wenhua West Road, Jinan 250012, Shandong Province, China. qifeng66321@sina.com

\section{Abstract}

\section{BACKGROUND}

Postoperative ileus is a frequent postoperative complication, especially after abdominal surgery. Sympathetic excitation is the primary factor for postoperative ileus. Sympathetic activation becomes increased by surgical stress, postoperative pain, and inflammation. Dexmedetomidine (DEX) can inhibit sympathetic nerve activity, inflammation, and pain.

AIM

To observe whether DEX promotes bowel movements in patients after laparoscopic nephrectomy.

\section{METHODS}

One hundred and twenty patients undergoing laparoscopic nephrectomy were assigned to three groups: C (normal saline infusion), D1 (DEX $0.02 \mu \mathrm{g} / \mathrm{kg} / \mathrm{h}$ ), and D2 (DEX $0.04 \mu \mathrm{g} / \mathrm{kg} / \mathrm{h}$ ). The primary outcomes were the recorded times to first flatus, defecation, and eating after surgery. The secondary outcomes were postoperative pain, assessed using the numerical rating scale (NRS), adverse effects, and the duration of the postoperative hospital stay.

\section{RESULTS}

The times to first flatus, defecation, and eating in groups D1 and D2 were significantly shorter than those in group $C(P<0.01)$. The NRS scores at $8 \mathrm{~h}$ and 24 $\mathrm{h}$ after surgery were significantly lower in groups D1 and D2 than in group $\mathrm{C}(P<$ 
chictr.org (ChiCTR-IPR-15007628).

Informed consent statement:

Informed consent was obtained

from all the participants.

Conflict-of-interest statement: No conflict of interest exists.

\section{Data sharing statement: No}

additional data are available.

CONSORT 2010 statement: This

manuscript was checked and

revised according to the

CONSORT 2010.

Open-Access: This article is an open-access article that was selected by an in-house editor and fully peer-reviewed by external reviewers. It is distributed in accordance with the Creative Commons Attribution NonCommercial (CC BY-NC 4.0) license, which permits others to distribute, remix, adapt, build upon this work non-commercially, and license their derivative works on different terms, provided the original work is properly cited and the use is non-commercial. See: htt p://creativecommons.org/License s/by-nc/4.0/

Manuscript source: Unsolicited manuscript

Specialty type: Anesthesiology

Country/Territory of origin: China

Peer-review report's scientific quality classification

Grade A (Excellent): 0

Grade B (Very good): B

Grade C (Good): C

Grade D (Fair): 0

Grade E (Poor): 0

Received: April 13, 2021

Peer-review started: April 13, 2021

First decision: May 11, 2021

Revised: May 16, 2021

Accepted: July 22, 2021

Article in press: July 22, 2021

Published online: September 16, 2021

P-Reviewer: Fujisawa M,

Heidenreich A

S-Editor: Wang JL

L-Editor: Wang TQ
$0.05)$. No adverse effects were observed $(P>0.05)$.

\section{CONCLUSION}

Postoperative infusion of DEX at $0.04 \mu \mathrm{g} / \mathrm{kg} / \mathrm{h}$ facilitates bowel movements in patients undergoing laparoscopic nephrectomy.

Key Words: Dexmedetomidine; Bowel movement; Recovery; Flatus; Postoperative

OThe Author(s) 2021. Published by Baishideng Publishing Group Inc. All rights reserved.

Core Tip: Postoperative ileus (POI) is a perplexing problem for clinical surgeons. In this study, laparoscopic nephrectomy was chosen to investigate postoperative gastrointestinal function recovery, avoiding damage to the gut itself. Based on the reported effects of DEX, the authors hypothesized that DEX could promote postoperative gastrointestinal function.

Citation: Huang SS, Song FX, Yang SZ, Hu S, Zhao LY, Wang SQ, Wu Q, Liu X, Qi F. Impact of intravenous dexmedetomidine on postoperative bowel movement recovery after laparoscopic nephrectomy: A consort-prospective, randomized, controlled trial. World J Clin Cases 2021; 9(26): 7762-7771

URL: https://www.wjgnet.com/2307-8960/full/v9/i26/7762.htm

DOI: https://dx.doi.org/10.12998/wjcc.v9.i26.7762

\section{INTRODUCTION}

Postoperative ileus (POI) is a perplexing problem for clinical surgeons. It occurs not only after abdominal surgery but also after any surgery that requires general anesthesia[1,2]. POI is defined as the dysfunction of gastrointestinal motility after surgery, characterized by a decrease in, or stagnation of, intestinal peristalsis. Common clinical manifestations include abdominal pain, abdominal distention, nausea, vomiting, delayed flatus, delayed defecation, and inability to consume orally [3-5]. POI is an uncomfortable experience, enhances the possibility of postoperative complications, prolongs hospital stay[4], and increases the economic burden[6,7]. Postoperative gastrointestinal function recovery is of great concern. There is currently an urgent need to improve postoperative recovery of gastrointestinal function.

The mechanism of POI varies, including autonomic regulation, inflammatory response, gastrointestinal hormones, and postoperative use of opioid drugs. Surgical gut damage destroys the intestinal barrier, stimulates the sympathetic and parasympathetic nervous system, and enhances the release of inflammatory factors $[1,5,8,9]$. These factors precipitate the occurrence of POIs. The current use of laparoscopic techniques can reduce incision size and surgical trauma, enabling careful manipulation[10-12]. Thus, the influence of the surgical procedure itself has decreased. Some studies have shown that intraoperative use of short-acting opioids or postoperative use of opioid receptor antagonists can ensure postoperative analgesia and eliminate the impact of intraoperative use of opioids on POI. Adjuvant epidural analgesia, intraoperative restriction of fluid intake, reduction of intraoperative blood loss, and early oral administration of nutrients after surgery can promote POI recovery[13]. However, POI remains a medical problem during clinical surgery; therefore, a more effective and noninvasive method is required.

Dexmedetomidine (DEX), as a highly selective $\alpha-2$ adrenergic receptor agonist, has the effects of synergetic analgesia, sedation, inhibition of sympathetic hyperactivity, and reduced release of inflammatory mediators with little respiratory inhibition[13, 14]. Previous studies on POI were all based on gastrointestinal tract surgery. Hence, in the present study, laparoscopic nephrectomy was chosen to investigate postoperative gastrointestinal function recovery, avoiding damage to the gut itself. Based on the reported effects of DEX, we hypothesized that DEX could promote postoperative gastrointestinal function. 
P-Editor: Liu JH

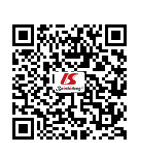

\section{MATERIALS AND METHODS}

\section{Participants}

This randomized, double-blinded, controlled trial was approved by the Institutional Medical Ethics Committee of Qilu Hospital of Shandong University. It was registered at chictr.org (ChiCTR-IPR-15007628) and is in accordance with the CONSORT guidelines. We chose patients who were treated by laparoscopic nephrectomy under general anesthesia at Qilu Hospital and did not have the following conditions: Body mass index greater than $32 \mathrm{~kg} / \mathrm{m}^{2}$ or less than $18 \mathrm{~kg} / \mathrm{m}^{2}$; age older than 75 or younger than 18 years; presence of bradycardia [basal heart rate (HR) less than $60 \mathrm{bpm}$ ] or other cardiac arrhythmia; presence of clinically significant dysfunction, including cardiovascular, renal, or hepatic diseases; previous history of chronic pain or long-term use of analgesics (at least $3 \mathrm{mo}$ ); or allergy to the test drug. This trial was initiated in January 2016 and terminated in December 2017.

\section{Randomization and masking}

The patients who met the enrollment criteria provided informed consent for participating in the trial. Then, according to a computer-generated randomization table, participants were randomly assigned to one of the three groups: $\mathrm{C}$ (normal saline infusion), D1 (DEX $0.02 \mu \mathrm{g} / \mathrm{kg} / \mathrm{h}$ ), and D2 (DEX $0.04 \mu \mathrm{g} / \mathrm{kg} / \mathrm{h}$ ). On the day of surgery, the drugs and patient-controlled analgesia (PCA) were prepared by an anesthetist who was blinded to the group assignment. Furthermore, the associated doctors and nurses were blinded to group assignment.

\section{Process of anesthesia}

Patients were premedicated with atropine $0.5 \mathrm{mg}$ by intramuscular injection in the ward. Before anesthesia induction, each patient was monitored for electrocardiography, noninvasive blood pressure measurements, pulse oximetry saturation $\left(\mathrm{SpO}_{2}\right)$, and end-tidal carbon dioxide $\left(\mathrm{EtCO}_{2}\right)$ using an automated system (Philips IntelliVue MP50; Philips Company, Beijing, China). $\mathrm{HR}, \mathrm{SpO}_{2}$, and mean blood pressure (MBP) were monitored every $5 \mathrm{~min}$.

After obtaining a baseline measurement of HR and MBP, groups D1 and D2 received $0.5 \% \mathrm{DEX}$, and group $\mathrm{C}$ received $0.9 \%$ normal saline for $10 \mathrm{~min}$. We used propofol, rocuronium, and sufentanil for sequential induction. The laryngeal mask airway (LMA) was intubated after positive pressure mask ventilation for $5 \mathrm{~min}$. An arterial cannula was required to monitor invasive arterial blood pressure in the left radial artery. Anesthetic depth was monitored using a bispectral index (BIS) monitor, and sevoflurane was administered to maintain the depth of anesthesia (BIS scores in the range of 40 to 60 ). Controlled ventilation was performed with $100 \%$ oxygen, and $\mathrm{EtCO}_{2}$ was maintained at $35-40 \mathrm{mmHg}$. We inserted a temperature probe through the nasal cavity and maintained the body temperature at $36-37^{\circ} \mathrm{C}$. We started to infuse the test drugs (groups D1 and D2 received the DEX infusion at rates of $0.2 \mu \mathrm{g} / \mathrm{kg} / \mathrm{h}$ and $0.4 \mu \mathrm{g} / \mathrm{kg} / \mathrm{h}$, respectively, while group $\mathrm{C}$ received saline instead of DEX) after the establishment of pneumoperitoneum and suspended them for $30 \mathrm{~min}$ before the end of surgery. Rocuronium was administered intermittently to maintain satisfactory muscle relaxation.

If more than a $20 \%$ fluctuation in the MBP baseline level was detected, vasoactive drugs (noradrenaline 5-10 $\mu \mathrm{g}$ or nitroglycerin 50-100 $\mu \mathrm{g}$ ) were used to maintain hemodynamic stability. If the HR decreased to less than $45 \mathrm{bpm}$, atropine $0.5 \mathrm{mg}$ was administered. Conversely, if the HR was greater than $100 \mathrm{bpm}$, esmolol $0.5 \mathrm{mg} / \mathrm{kg}$ was administered to decrease the HR. When the laparoscope was withdrawn, palonosetron $(0.25 \mathrm{mg})$ was intravenously administered to prevent postoperative nausea and vomiting (PONV). When spontaneous breathing appeared at the end of the surgery, neostigmine $0.04 \mathrm{mg} / \mathrm{kg}$ and atropine $0.02 \mathrm{mg} / \mathrm{kg}$ were administered to antagonize neuromuscular blockade before LMA extubation. If the $\mathrm{SpO}_{2}$ was greater than $90 \%$ without oxygen for at least $5 \mathrm{~min}$, patients could be sent back to the ward.

At the end of the surgery, a PCA pump was started (group C with sufentanil 0.02 $\mu \mathrm{g} / \mathrm{kg} / \mathrm{h}$; group D1 with both sufentanil and DEX $0.02 \mu \mathrm{g} / \mathrm{kg} / \mathrm{h}$; group D2 with sufentanil $0.02 \mu \mathrm{g} / \mathrm{kg} / \mathrm{h}$ and DEX $0.04 \mu \mathrm{g} / \mathrm{kg} / \mathrm{h})$. The PCA was programmed to deliver at a constant speed of $2 \mathrm{~mL} / \mathrm{h}$, and an additional dose $(0.5 \mathrm{~mL})$ was administered with a lockout time of $10 \mathrm{~min}$.

Regarding postoperative bowel movements, patients were given abdominal massage, miso soup, or both if the time to flatus was more than $48 \mathrm{~h}$. Intravenous nutrition was provided if the time to flatus was more than $72 \mathrm{~h}$. 


\section{Outcomes}

The primary outcome measures were the times to first flatus and defecation, and the duration of postoperative hospital stay. The secondary outcome measures were postoperative pain scores, both at rest and during movement, and adverse effects.

$\mathrm{HR}, \mathrm{MBP}$, and $\mathrm{SpO}_{2}$ were collected at the following six time points: Entering the operating room (T0), $5 \mathrm{~min}$ after finishing the baseline test drug infusion (T1), $5 \mathrm{~min}$ after pneumoperitoneum establishment (T2), $1 \mathrm{~h}$ after pneumoperitoneum establishment (T3), $2 \mathrm{~h}$ after pneumoperitoneum establishment (T4), and 5 min after extubation (T5). In addition, $\mathrm{EtCO}_{2}$ was recorded from T1 to T4. Pain scores were assessed using the numerical rating scale (NRS) $(0=$ no pain to $10=$ worst pain $)$ at 1,8 , 24 , and $48 \mathrm{~h}$ postoperatively.

\section{Statistical analysis}

Statistical analyses were performed using SPSS software (version 21.0, SPSS Inc. Chicago, IL, USA). The Kolmogorov-Smirnov test was used to assess the distribution of the variables. Levene's test was used to compare the homogeneity of variance among the three groups. Normally distributed data are expressed as the mean and standard deviation, whereas data with a skewed distribution are expressed as the median and number $(n)$. Percentages (\%) are used to represent categorical data. Parameters such as age, operation time, anesthesia time, time to first flatus and defecation, MBP, and HR among these groups were compared using two-way analysis of variance. The Mann-Whitney test was used to evaluate the NRS scores among the three groups, and adverse reactions were analyzed using the $\chi^{2}$ test. Multiple comparisons were performed using the LSD post-hoc test. Statistical significance was set at $P<0.05$.

\section{RESULTS}

A total of 123 patients were randomly distributed into three groups. Among the patients, two were eliminated due to conversion to open nephrectomy (one from group D1 and one from group D2). In addition, one patient was excluded after surgery because of incomplete clinical data (from group C) (Figure 1). The baseline characteristics and demographics of the patients were comparable among the three groups (Table 1).

The times to first flatus and defecation after surgery in groups D1 (41.50 $\pm 8.24 \mathrm{~h}$ and $73.33 \pm 19.19 \mathrm{~h}$, respectively) and D2 (38.66 $\pm 7.60 \mathrm{~h}$ and $71.33 \pm 19.70 \mathrm{~h}$, respectively) were significantly shorter than those in group C $(51.31 \pm 11.78 \mathrm{~h}$ and $92.80 \pm 25.51 \mathrm{~h}$, respectively, $P<0.05$; Table 2$)$. The time to eating after surgery in groups D1 (44.50 \pm $8.94 \mathrm{~h})$ and D2 $(42.29 \pm 7.75 \mathrm{~h})$ was shorter than that in group $\mathrm{C}(54.78 \pm 11.58 \mathrm{~h})(P<$ 0.05 ; Table 2).

MBP at T1 in groups D1 and D2 was significantly lower than that in group C. MBP was lower than the baseline at T2, T3, T4, and T5 in group C, and at T1 and T4 in groups D1 and D2 $(P<0.05$, Table 3$)$. HR at T1 and T2 in group D1 was significantly lower than that in group $\mathrm{C}$. HR was lower than the baseline at T2, T3, and T4 in group $\mathrm{C}$, and at T1, T2, T3, and T4 in groups D1 and D2 $(P<0.05$; Table 3$)$. The NRS scores at rest or with movement at $8 \mathrm{~h}$ and $24 \mathrm{~h}$ after surgery were significantly lower in groups D1 and D2 than in group C $(P<0.05$; Figure 2$)$.

Adverse effects were not significantly different among the three groups $(P>0.05$; Table 4).

\section{DISCUSSION}

The perioperative use of $0.04 \mu \mathrm{g} / \mathrm{kg} / \mathrm{h}$ DEX enhanced the recovery of postoperative gastrointestinal function in our study.

Experts agree that patients with POI present with several related symptoms, such as abdominal pain and distension, nausea, vomiting, absence of normal bowel sounds, intolerance of oral intake, and difficulty in defecation[15]. We did not observe the time at which bowel sounds occurred in our study because such data is subjective.

POI occurs temporarily after surgery and is not caused by mechanical reasons[15]. The mechanism of POI is complicated and involves many factors, in particular, the regulation of sympathetic and parasympathetic nerves, the inflammatory response, and postoperative use of opioid drugs. In this study, we observed the influence of DEX on the postoperative outcomes of nephrectomy to avoid gut damage. 
Table 1 Clinical characteristics of patients in groups C, D1, and D2

\begin{tabular}{|c|c|c|c|c|}
\hline & Group C $(n=40)$ & Group D1 $(n=40)$ & Group D2 $(n=40)$ & $P$ value \\
\hline Sex, F/M & $11 / 29$ & $12 / 28$ & $10 / 30$ & 0.8820 \\
\hline Age, yr & $52.73 \pm 10.68$ & $52.33 \pm 7.99$ & $51.73 \pm 8.58$ & 0.886 \\
\hline BMI, $\mathrm{kg} / \mathrm{m}^{2}$ & $25.58 \pm 2.70$ & $26.15 \pm 1.70$ & $25.95 \pm 2.04$ & 0.505 \\
\hline Hypertension, Yes/No & $11 / 29$ & $12 / 28$ & $15 / 25$ & 0.606 \\
\hline DM, Yes/No & $6 / 34$ & $5 / 35$ & $5 / 35$ & 0.930 \\
\hline ASA, I/II & $10 / 30$ & $7 / 33$ & $6 / 34$ & 0.497 \\
\hline Duration of anaesthesia, min & $148.95 \pm 49.54$ & $145.90 \pm 47.24$ & $144.60 \pm 50.24$ & 0.920 \\
\hline Duration of surgery, min & $128.48 \pm 46.83$ & $130.90 \pm 47.13$ & $127.33 \pm 50.18$ & 0.944 \\
\hline Dosage of sufentanil during surgery, $\mu \mathrm{g}$ & $32.58 \pm 7.20$ & $31.63 \pm 3.28$ & $32.75 \pm 3.91$ & 0.570 \\
\hline Dosage of sufentanil after surgery $(8 \mathrm{~h}), \mathrm{mL}$ & $16.35 \pm 0.51$ & $16.15 \pm 0.43$ & $16.29 \pm 0.53$ & 0.180 \\
\hline Dosage of sufentanil after surgery $(24 \mathrm{~h}), \mathrm{mL}$ & $48.41 \pm 0.59$ & $48.26 \pm 0.76$ & $48.30 \pm 0.60$ & 0.566 \\
\hline Postoperative stay in hospital, $\mathrm{d}$ & $8.60 \pm 1.72$ & $8.38 \pm 1.35$ & $8.43 \pm 1.68$ & 0.803 \\
\hline
\end{tabular}

Variables are presented as the mean \pm SD or number of patients. None showed any statistical significance $(P>0.05)$. ASA: American Society of Anesthesiologists, BMI: Body mass index, DM: Diabetes mellitus.

Table 2 Bowel movement after surgery in groups C, D1, and D2

\begin{tabular}{lllll}
\hline & Group C $(\boldsymbol{n}=\mathbf{4 0})$ & Group D1 $(\boldsymbol{n}=\mathbf{4 0})$ & Group D2 $(\boldsymbol{n}=\mathbf{4 0})$ & $\boldsymbol{P}$ valves \\
\hline Time to first flatus, h & $51.31 \pm 11.78$ & $41.50 \pm 8.24$ & $38.66 \pm 7.60$ & $0.001^{1} / 0.001^{2} / 0.179^{3}$ \\
Time to defecation, h & $92.80 \pm 25.51$ & $73.33 \pm 19.19$ & $71.33 \pm 19.70$ & $0.001^{1} / 0.001^{2} / 0.680^{3}$ \\
Time to eating, h & $54.78 \pm 11.58$ & $44.50 \pm 8.94$ & $42.29 \pm 7.75$ & $0.001^{1} / 0.001^{2} / 0.303^{3}$ \\
\hline
\end{tabular}

\footnotetext{
${ }^{1}$ Group D1 vs group C.

${ }^{2}$ Group D2 vs group C.

${ }^{3}$ Group D1 vs group D2. Variables are presented as the mean \pm SD.
}

Gastrointestinal peristalsis mainly depends on parasympathetic stimulation and is inhibited by sympathetic stimulation. Sympathetic hyperactivity is considered one of the main causes of postoperative intestinal paralysis[3,5]. Surgery, pain, gut damage, $\mathrm{CO}_{2}$ used to establish pneumoperitoneum, and other factors directly or indirectly activate the sympathetic nerves and inhibit postoperative gastrointestinal function recovery. Activated sympathetic nerves increase the release of catecholamines, which inhibit postoperative gastrointestinal function by restricting intestinal smooth muscle contraction[16,17]. DEX is a highly selective $\alpha 2$-adrenoceptor agonist that acts on $\alpha 2$ adrenoceptors in the central nervous system to reduce the upregulation of sympathetic nerve activation and decrease catecholamine release[18]. Consequently, we firmly believe that treatment with DEX could inhibit sympatholytic excitation, reduce catecholamine activation, excite the parasympathetic nerves, and facilitate postoperative gastrointestinal function. Shorter times to flatus and defecation were observed in our study, which was in accordance with our hypothesis.

Surgical stress and gut damage activate the intestinal immune system, causing the release of inflammatory factors. Inflammatory factors released due to intestinal injury increase intestinal permeability and damage the intestinal lining. White blood cells can easily migrate to the muscle layer, and inflammatory substances can inhibit smooth muscle contraction and weaken gastrointestinal peristalsis[19]. DEX treatment enhances postoperative intestinal function, as it increases the efferent activity of the parasympathetic nerves, the release of acetylcholine, and the expression level of $\alpha 7$ nicotinic acetylcholine receptor $(\alpha 7 \mathrm{nAchR})$, and reduces the release of some inflammatory transmitters[20,21]. DEX was also found to play an anti-inflammatory role through $\alpha 7 \mathrm{nAchR}$, reducing postoperative intestinal inflammation and promoting the recovery of intestinal function[22]. Better gastrointestinal function was observed after 


\begin{tabular}{|c|c|c|c|c|}
\hline Time point & Group C $(n=40)$ & Group D1 $(n=40)$ & Group D2 $(n=40)$ & $P$ value \\
\hline \multicolumn{5}{|l|}{ MBP, mm Hg } \\
\hline т0 & $103.80 \pm 11.34$ & $99.73 \pm 11.28$ & $99.53 \pm 9.91$ & 0.144 \\
\hline $\mathrm{T} 1$ & $101.53 \pm 9.45$ & $88.88 \pm 13.07^{\mathrm{a}, \mathrm{c}}$ & $87.65 \pm 12.71^{\mathrm{a}, \mathrm{c}}$ & 0.001 \\
\hline $\mathrm{T} 2$ & $98.90 \pm 9.81^{\mathrm{a}}$ & $98.88 \pm 11.65$ & $97.85 \pm 12.53$ & 0.895 \\
\hline $\mathrm{T} 3$ & $97.40 \pm 10.11^{\mathrm{a}}$ & $96.38 \pm 7.78$ & $95.88 \pm 8.72$ & 0.739 \\
\hline $\mathrm{T} 4$ & $98.88 \pm 8.33^{\mathrm{a}}$ & $94.58 \pm 9.62^{a, c}$ & $93.83 \pm 8.54^{a, c}$ & 0.025 \\
\hline T5 & $105.45 \pm 13.24^{\mathrm{a}}$ & $102.50 \pm 13.55$ & $102.38 \pm 12.14$ & 0.490 \\
\hline \multicolumn{5}{|l|}{ HR, bpm } \\
\hline T0 & $75.93 \pm 11.18$ & $71.43 \pm 9.48$ & $74.30 \pm 8.70$ & 0.122 \\
\hline $\mathrm{T} 1$ & $74.78 \pm 10.22$ & $63.56 \pm 10.96^{a, c}$ & $65.88 \pm 8.56^{\mathrm{a}, \mathrm{c}}$ & 0.001 \\
\hline $\mathrm{T} 2$ & $64.88 \pm 7.74^{a}$ & $59.80 \pm 10.02^{\mathrm{a}, \mathrm{c}}$ & $63.48 \pm 6.93^{\mathrm{a}}$ & 0.022 \\
\hline $\mathrm{T} 3$ & $66.43 \pm 11.53^{\mathrm{a}}$ & $62.45 \pm 9.01^{a}$ & $65.53 \pm 7.97^{\mathrm{a}}$ & 0.158 \\
\hline $\mathrm{T} 4$ & $67.30 \pm 10.47^{\mathrm{a}}$ & $66.05 \pm 11.08^{\mathrm{a}}$ & $67.55 \pm 9.85^{\mathrm{a}}$ & 0.791 \\
\hline T5 & $75.80 \pm 9.32$ & $73.05 \pm 9.86$ & $72.90 \pm 6.20$ & 0.242 \\
\hline
\end{tabular}

${ }^{\mathrm{a}} P<0.05$ vs baseline.

${ }^{\mathrm{c}} P<0.05$ vs group $\mathrm{C}$. Variables are presented as the mean \pm SD. MBP: Mean blood pressure; HR: Heart rate.

Table 4 Adverse reactions after surgery in groups C, D1, and D2, $n(\%)$

\begin{tabular}{lllll}
\hline & Group C $(\boldsymbol{n = 4 0 )}$ & Group D1 $(\boldsymbol{n}=\mathbf{4 0})$ & Group D2 $(\boldsymbol{n}=\mathbf{4 0})$ & $\boldsymbol{P}$ values \\
\hline Abdominal massage/simo soup & $5(12.5)$ & $3(7.5)$ & $2(5)$ & 0.466 \\
Intravenous nutrition & $0(0)$ & $0(0)$ & $0(0)$ & 1.000 \\
Nausea and vomiting & $8(20)$ & $7(17.5)$ & $8(20)$ & 0.948 \\
Severe abdominal pain and distention & $6(15)$ & $5(12.5)$ & $4(10)$ & 0.796 \\
Drowsiness & $1(2.5)$ & $2(5)$ & $4(10)$ & 0.346 \\
Serious respiratory depression & $0(0)$ & $0(0)$ & $0(0)$ & 1.000 \\
Delirium & $0(0)$ & $0(0)$ & $0(0)$ & 1.000 \\
\hline
\end{tabular}

the use of DEX in our study, which verified our hypothesis.

Visualizing laparoscopic surgery and pneumoperitoneum induction can lead to sympathetic nerve activation[16,23]. In addition, $\mathrm{CO}_{2}$ pneumoperitoneum can induce hypercarbia, which can directly or indirectly stimulate the sympathetic nervous system and cause elevated levels of catecholamines[16,24]. These factors lead to greater excitability of sympathetic nerves than parasympathetic nerves. Subsequently, gastrointestinal function is inhibited, and POI occurs. DEX, a highly selective $\alpha-2$ adrenergic receptor agonist, acts on $\alpha 2$-adrenoceptors in the central nervous system to reduce sympathetic nerve activation and decrease catecholamine secretion[24,25]. DEX has been proven to attenuate sympathetic nerve activation induced by pneumoperitoneum and surgical stress[26], and to decrease the inflammatory response[20] to facilitate postoperative bowel movements. Groups D1 and D2 had significantly shorter times to flatus and defecation in our study than group C. Although group D2 had shorter times to flatus and defecation than group D1, and the difference was not significant for patients in the clinic, the observed 1-h difference is still important. This study provided evidence for the relief of postoperative gastrointestinal function in patients undergoing endoscopic surgery.

Although opioids are a priority for postoperative pain, they are unfavorable because they inhibit gastrointestinal motility and aggravate POI[27-29]. The perioperative use of DEX has been previously reported to relieve postoperative pain and reduce the total 


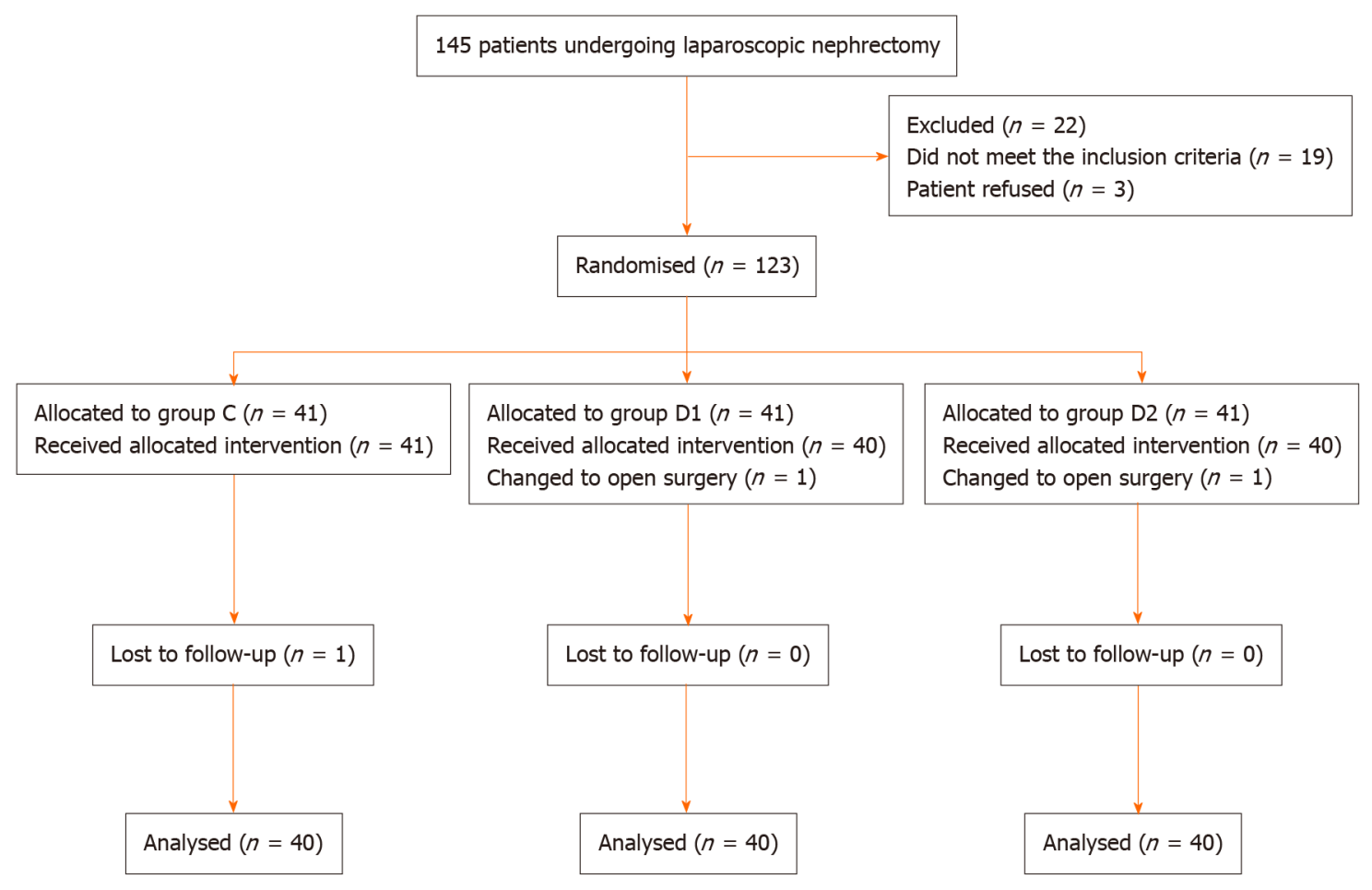

Figure 1 Patient enrolment flow diagram. This illustrates the flow of all patients screened, excluded, and randomized.

volume of opioids required[30,31]. The total volume of opioid drugs used in our study did not differ among the three groups, which may be due to a reduced level of postoperative pain experienced following laparoscopic surgery compared with that associated with open surgery. However, the use of DEX still significantly relieved postoperative pain with rest and movement at $8 \mathrm{~h}$ and $24 \mathrm{~h}$ after surgery in our study. Effective pain relief contributed to the alleviation of POI and allowed patients who received DEX to resume activity earlier postoperatively than those who did not. We hypothesized that DEX accelerated gastrointestinal function to relieve postoperative pain.

The blood vessels contracted when DEX was administered as a bolus, and hypertension was observed in the first 1-3 min. Hypertension has been observed but not measured in other studies, and when DEX was used as an infusion drug, its central sympatholytic effect was the main effect[32,33]. The incidence of bradycardia and hypotension (requiring treatment) was increased only when a loading and maintenance dose of DEX $>0.07 \mu \mathrm{g} / \mathrm{kg} / \mathrm{h}$ was given to critically ill patients[34]. The HR and MBP were significantly lower but without evidence of bradycardia and hypotension after treatment with the loading dose of DEX in our study. The infusion of DEX during anesthesia resulted in medium variations in MBP and HR among the three groups, but the difference was not significant. These findings are in accordance with those of previous reports[35,36]. There was no significant difference in HR and MBP among the three groups; therefore, the two doses of DEX used were both safe for the patients.

DEX produces sedation with minimal respiratory inhibition[37]. No respiratory inhibition was observed in the present study. There were no significant differences in easily arousable drowsiness, PONV, or postoperative delirium among the groups.

Our study had some limitations. First, DEX was administered at a rate of $0.5 \mathrm{mg} / \mathrm{kg}$ for $10 \mathrm{~min}$ before the induction of anesthesia and then at a rate of 0.2 to $0.4 \mu \mathrm{g} / \mathrm{kg} / \mathrm{h}$ during the operation. However, we were unable to determine the effect of plasma DEX concentrations on intraoperative hemodynamics because we did not measure the serum concentrations of DEX at any time point. Finally, laparoscopic nephrectomy was performed using two different surgical methods: Transabdominal and retroperitoneal. Therefore, different surgical techniques might have had different effects on postoperative analgesia and recovery of gastrointestinal function. 

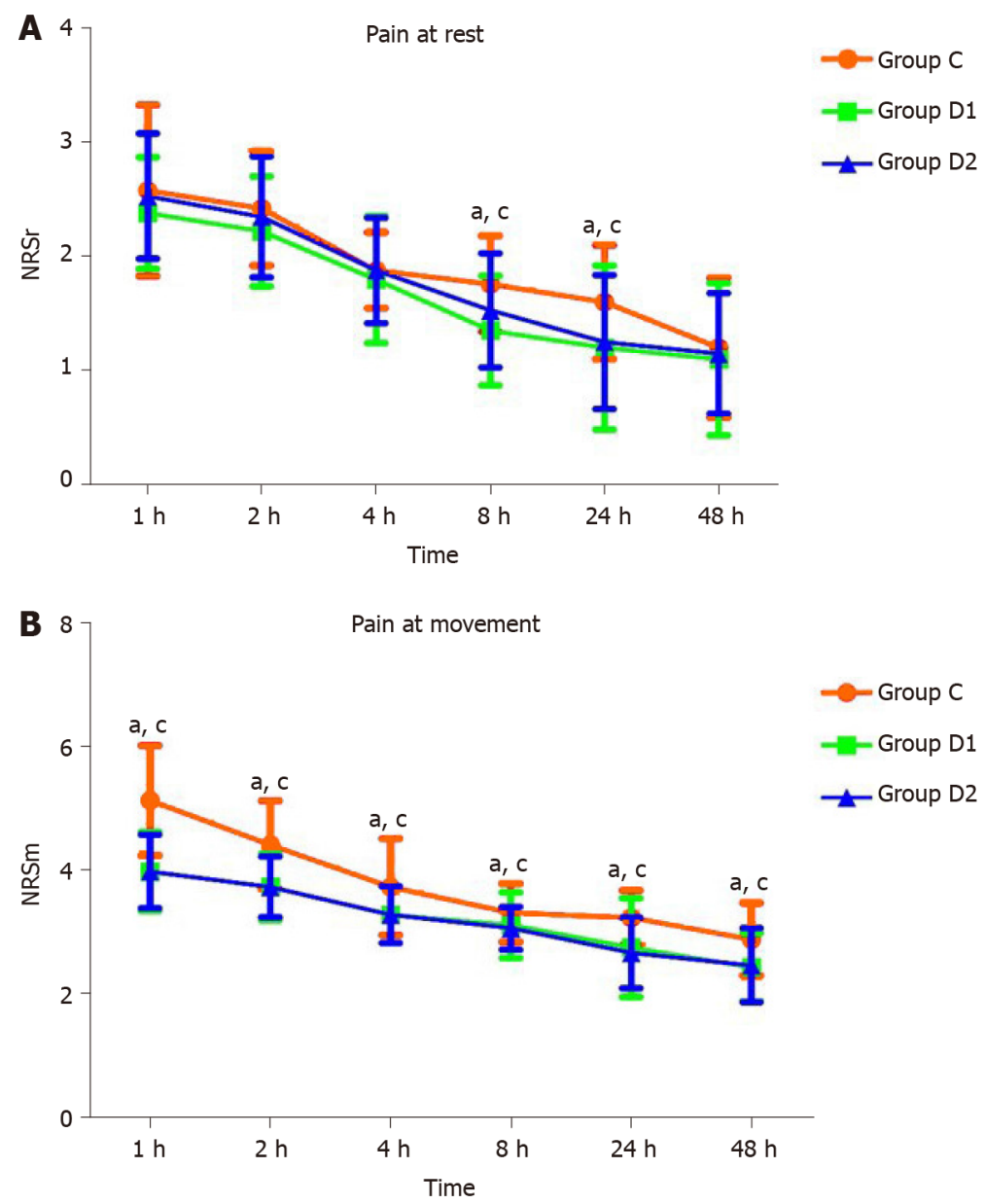

Figure 2 Pain scores during $48 \mathrm{~h}$ after surgery in groups C, D1, and D2. Variables are presented as the mean $\pm \mathrm{SD}$. The numerical rating scale scores at $8 \mathrm{~h}$ and $24 \mathrm{~h}$ were significantly lower in groups D1 and D2 than in group $C$ at rest and at movement. a $P<0.05$, group D1 vs group $C$; ${ }^{c} P<0.05$, group D2 vs group C. NRS: Numerical rating scale.

\section{CONCLUSION}

Perioperative DEX infusion at $0.04 \mu \mathrm{g} / \mathrm{kg} / \mathrm{h}$ resulted in better and faster recovery of gastrointestinal function and a more favorable analgesic effect without additional adverse effects in patients who underwent laparoscopic nephrectomy.

\section{ARTICLE HIGHLIGHTS}

\section{Research background}

Postoperative ileus (POI) is a perplexing problem for clinical surgeons. POI occurs not only after abdominal surgery, but also after any other surgery that requires general anesthesia.

\section{Research motivation}

Regarding enhanced recovery after surgery, postoperative gastrointestinal function recovery is of great concern. Currently, there is an urgent need to improve postoperative recovery of gastrointestinal function.

\section{Research objectives}

This study aimed to observe whether dexmedetomidine (DEX) promotes bowel movements in patients after laparoscopic nephrectomy

\section{Research methods}

A total of 120 patients who underwent laparoscopic nephrectomy were assigned into three groups: C (normal saline infusion), D1 (DEX $0.02 \mu \mathrm{g} / \mathrm{kg} / \mathrm{h}$ ), and D2 (DEX 0.04 
$\mu \mathrm{g} / \mathrm{kg} / \mathrm{h})$

\section{Research results}

Mean blood pressure (MBP) at T1 in groups D1 and D2 was significantly lower than that in group C. MBP was lower than the baseline at T2, T3, T4, and T5 in group C, and at $\mathrm{T} 1$ and $\mathrm{T} 4$ in groups D1 and D2.

\section{Research conclusions}

Perioperative DEX infusion at $0.04 \mu \mathrm{g} / \mathrm{kg} / \mathrm{h}$ resulted in better and faster recovery of gastrointestinal function and a more favorable analgesic effect without additional adverse effects in patients who underwent laparoscopic nephrectomy.

\section{Research perspectives}

This study suggests a new method for postoperative intestinal function recovery.

\section{REFERENCES}

1 Deng WW, Lan M, Peng AF, Chen T, Li ZQ, Liu ZL, Liu JM. The risk factors for postoperative ileus following posterior thoraco-lumbar spinal fusion surgery. Clin Neurol Neurosurg 2019; 184: 105411 [PMID: 31310924 DOI: 10.1016/j.clineuro.2019.105411]

2 Petca A, Borislavschi A, Dumitrascu MC, Sandru F, Geoarsa M, Petca RC. Postoperative Ileus Complicated with Incomplete Evisceration after Hysterectomy for Benign Pathology. Chirurgia (Bucur) 2020; 115: 112-119 [PMID: 32155406 DOI: 10.21614/chirurgia.115.1.112]

3 Holte K, Kehlet H. Postoperative ileus: a preventable event. Br J Surg 2000; 87: 1480-1493 [PMID: 11091234 DOI: $10.1046 / j .1365-2168.2000 .01595 . x]$

4 Tevis SE, Carchman EH, Foley EF, Harms BA, Heise CP, Kennedy GD. Postoperative Ileus--More than Just Prolonged Length of Stay? J Gastrointest Surg 2015; 19: 1684-1690 [PMID: 26105552 DOI: $10.1007 / \mathrm{s} 11605-015-2877-1]$

5 Venara A, Neunlist M, Slim K, Barbieux J, Colas PA, Hamy A, Meurette G. Postoperative ileus: Pathophysiology, incidence, and prevention. J Visc Surg 2016; 153: $439-446$ [PMID: 27666979 DOI: 10.1016/j.jviscsurg.2016.08.010]

6 Iyer S, Saunders WB, Stemkowski S. Economic burden of postoperative ileus associated with colectomy in the United States. J Manag Care Pharm 2009; 15: 485-494 [PMID: 19610681 DOI: 10.18553/jmcp.2009.15.6.485]

7 Asgeirsson T, El-Badawi KI, Mahmood A, Barletta J, Luchtefeld M, Senagore AJ. Postoperative ileus: it costs more than you expect. J Am Coll Surg 2010; 210: 228-231 [PMID: 20113944 DOI: 10.1016/j.jamcollsurg.2009.09.028]

8 Chapuis PH, Bokey L, Keshava A, Rickard MJ, Stewart P, Young CJ, Dent OF. Risk factors for prolonged ileus after resection of colorectal cancer: an observational study of 2400 consecutive patients. Ann Surg 2013; 257: 909-915 [PMID: 23579542 DOI: 10.1097/SLA.0b013e318268a693]

9 Bragg D, El-Sharkawy AM, Psaltis E, Maxwell-Armstrong CA, Lobo DN. Postoperative ileus: Recent developments in pathophysiology and management. Clin Nutr 2015; 34: 367-376 [PMID: 25819420 DOI: 10.1016/j.clnu.2015.01.016]

10 Okholm C, Goetze JP, Svendsen LB, Achiam MP. Inflammatory response in laparoscopic vs. open surgery for gastric cancer. Scand J Gastroenterol 2014; 49: 1027-1034 [PMID: 24852697 DOI: 10.3109/00365521.2014.917698]

11 Wormser C, Runge JJ. Advances in Laparoscopic Surgery. Vet Clin North Am Small Anim Pract 2016; 46: 63-84 [PMID: 26604155 DOI: 10.1016/j.cvsm.2015.08.001]

12 Best LM, Mughal M, Gurusamy KS. Laparoscopic vs open gastrectomy for gastric cancer. Cochrane Database Syst Rev 2016; 3: CD011389 [PMID: 27030300 DOI: 10.1002/14651858.CD011389.pub2]

13 Kehlet H, Wilmore DW. Evidence-based surgical care and the evolution of fast-track surgery. Ann Surg 2008; 248: 189-198 [PMID: 18650627 DOI: 10.1097/SLA.0b013e31817f2c1a]

14 Zhang X, Zhao X, Wang Y. Dexmedetomidine: a review of applications for cardiac surgery during perioperative period. $J$ Anesth 2015; 29: 102-111 [PMID: 24913070 DOI: 10.1007/s00540-014-1857-z]

15 Gero D, Gié O, Hübner M, Demartines N, Hahnloser D. Postoperative ileus: in search of an international consensus on definition, diagnosis, and treatment. Langenbecks Arch Surg 2017; 402: 149-158 [PMID: 27488952 DOI: 10.1007/s00423-016-1485-1]

16 Chen Y, Xie Y, Xue Y, Wang B, Jin X. Effects of ultrasound-guided stellate ganglion block on autonomic nervous function during CO2-pneumoperitoneum: A randomized double-blind control trial. J Clin Anesth 2016; 32: 255-261 [PMID: 27290985 DOI: 10.1016/j.jclinane.2016.03.019]

17 Rasmussen JP, Dauchot PJ, DePalma RG, Sorensen B, Regula G, Anton AH, Gravenstein JS. Cardiac function and hypercarbia. Arch Surg 1978; 113: 1196-1200 [PMID: 708241 DOI: 10.1001/archsurg.1978.01370220082013]

18 Khan ZP, Ferguson CN, Jones RM. alpha-2 and imidazoline receptor agonists. Their pharmacology and therapeutic role. Anaesthesia 1999; 54: 146-165 [PMID: 10215710 DOI: 
10.1046/j.1365-2044.1999.00659.x]

19 Kehlet H, Holte K. Review of postoperative ileus. Am J Surg 2001; 182: 3S-10S [PMID: 11755891 DOI: 10.1016/s0002-9610(01)00781-4]

20 Wehner S, Straesser S, Vilz TO, Pantelis D, Sielecki T, de la Cruz VF, Hirner A, Kalff JC. Inhibition of p38 mitogen-activated protein kinase pathway as prophylaxis of postoperative ileus in mice. Gastroenterology 2009; 136: 619-629 [PMID: 19014943 DOI: 10.1053/j.gastro.2008.10.017]

21 Yu T, Liu D, Gao M, Yang P, Zhang M, Song F, Zhang X, Liu Y. Dexmedetomidine prevents septic myocardial dysfunction in rats via activation of $\alpha 7 \mathrm{nAChR}$ and PI3K/Akt- mediated autophagy. Biomed Pharmacother 2019; 120: 109231 [PMID: 31546082 DOI: 10.1016/j.biopha.2019.109231]

22 Xiang H, Hu B, Li Z, Li J. Dexmedetomidine controls systemic cytokine levels through the cholinergic anti-inflammatory pathway. Inflammation 2014; 37: 1763-1770 [PMID: 24803295 DOI: 10.1007/s10753-014-9906-1]

23 Rohloff M, Cicic A, Christensen C, Maatman TK, Lindberg J, Maatman TJ. Reduction in postoperative ileus rates utilizing lower pressure pneumoperitoneum in robotic-assisted radical prostatectomy. J Robot Surg 2019; 13: 671-674 [PMID: 30604275 DOI: 10.1007/s11701-018-00915-w]

24 Cioccari L, Luethi N, Bailey M, Shehabi Y, Howe B, Messmer AS, Proimos HK, Peck L, Young H, Eastwood GM, Merz TM, Takala J, Jakob SM, Bellomo R; ANZICS Clinical Trials Group and the SPICE III Investigators. The effect of dexmedetomidine on vasopressor requirements in patients with septic shock: a subgroup analysis of the Sedation Practice in Intensive Care Evaluation [SPICE III] Trial. Crit Care 2020; 24: 441 [PMID: 32678054 DOI: 10.1186/s13054-020-03115-x]

25 Peng Y, Zhu H, Chen H, Zhu Z, Zhou H, Zhang S, Gao L, Shi L, Li X, Luo Z. Dexmedetomidine attenuates acute paroxysmal sympathetic hyperactivity. Oncotarget 2017; 8: 69012-69019 [PMID: 28978176 DOI: 10.18632/oncotarget.16920]

26 Kim NY, Han DW, Koh JC, Rha KH, Hong JH, Park JM, Kim SY. Effect of Dexmedetomidine on Heart Rate-Corrected QT and Tpeak-Tend Intervals During Robot-Assisted Laparoscopic Prostatectomy With Steep Trendelenburg Position: A Prospective, Randomized, Double-Blinded, Controlled Study. Medicine (Baltimore) 2016; 95: e3645 [PMID: 27175685 DOI: 10.1097/MD.0000000000003645]

27 Momeni M, Crucitti M, De Kock M. Patient-controlled analgesia in the management of postoperative pain. Drugs 2006; 66: 2321-2337 [PMID: 17181375 DOI: 10.2165/00003495-200666180-00005]

28 Gelman D, Gelmanas A, Urbanaitè D, Tamošiūnas R, Sadauskas S, Bilskienė D, Naudžiūnas A, Širvinskas E, Benetis R, Macas A. Role of Multimodal Analgesia in the Evolving Enhanced Recovery after Surgery Pathways. Medicina (Kaunas) 2018; 54 [PMID: 30344251 DOI: 10.3390/medicina54020020]

29 de Boer HD, Detriche O, Forget P. Opioid-related side effects: Postoperative ileus, urinary retention, nausea and vomiting, and shivering. A review of the literature. Best Pract Res Clin Anaesthesiol 2017; 31: 499-504 [PMID: 29739538 DOI: 10.1016/j.bpa.2017.07.002]

30 Abdel Hamid MHE. Intravenous Dexmedetomidine Infusion Compared with that of Fentanyl in Patients Undergoing Arthroscopic Shoulder Surgery under General Anesthesia. Anesth Essays Res 2017; 11: 1070-1074 [PMID: 29284877 DOI: 10.4103/aer.AER_148_17]

31 Sharma R, Gupta R, Choudhary R, Singh Bajwa SJ. Postoperative Analgesia with Intravenous Paracetamol and Dexmedetomidine in Laparoscopic Cholecystectomy Surgeries: A Prospective Randomized Comparative Study. Int J Appl Basic Med Res 2017; 7: 218-222 [PMID: 29308357 DOI: 10.4103/ijabmr.IJABMR_25_17]

32 Hall JE, Uhrich TD, Ebert TJ. Sedative, analgesic and cognitive effects of clonidine infusions in humans. Br J Anaesth 2001; 86: 5-11 [PMID: 11575409 DOI: 10.1093/bja/86.1.5]

33 Ebert TJ, Hall JE, Barney JA, Uhrich TD, Colinco MD. The effects of increasing plasma concentrations of dexmedetomidine in humans. Anesthesiology 2000; 93: 382-394 [PMID: 10910487 DOI: $10.1097 / 00000542-200008000-00016]$

34 Tan JA, Ho KM. Use of dexmedetomidine as a sedative and analgesic agent in critically ill adult patients: a meta-analysis. Intensive Care Med 2010; 36: $926-939$ [PMID: 20376429 DOI: 10.1007/s00134-010-1877-6]

35 Venn RM, Grounds RM. Comparison between dexmedetomidine and propofol for sedation in the intensive care unit: patient and clinician perceptions. Br J Anaesth 2001; 87: 684-690 [PMID: 11878517 DOI: $10.1093 / \mathrm{bja} / 87.5 .684]$

36 Kabukçu HK, Sahin N, Temel Y, Titiz TA. Hemodynamics in coronary artery bypass surgery: effects of intraoperative dexmedetomidine administration. Anaesthesist 2011; 60: 427-431 [PMID: 21271232 DOI: 10.1007/s00101-010-1842-3]

37 Keating GM. Dexmedetomidine: A Review of Its Use for Sedation in the Intensive Care Setting. Drugs 2015; 75: 1119-1130 [PMID: 26063213 DOI: 10.1007/s40265-015-0419-5] 


\section{DS \\ Baishideng ${ }^{\circledR}$}

Published by Baishideng Publishing Group Inc

7041 Koll Center Parkway, Suite 160, Pleasanton, CA 94566, USA

Telephone: +1-925-3991568

E-mail: bpgoffice@wignet.com

Help Desk: https:/ /www.f6publishing.com/helpdesk

https://www.wjgnet.com

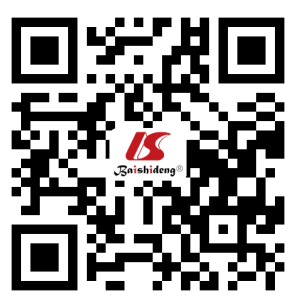

